\title{
Validation and Evaluation of an OSCE in Undergraduate Doctor of Pharmacy Program
}

\author{
Ali Almuqdadi, Al-Motassem Yousef, Khalil Majdalawi, Zeina Masoud, Reem Kalabani, \\ Hanadi Al-hadeed
}

Department of Bio pharmaceutics and Clinical Pharmacy, Faculty of Pharmacy, The University of JORDAN, Amman, 11942, Queen

Rania Street, JORDAN.

\begin{abstract}
Introduction and purpose: In schools not performing OSCE method, faculty members' lack of time, human resources and managing the complexity of such exam are the most common obstacles. In this study, we utilized different methods to evaluate the the validity and reliability of a simple diversified OSCE as part of final exam for ambulatory care clerkship along with the theoretical exam. Methods: We analyzed the correlation and difference between students' achievements in the written exam and their achievements in OSCE. We also compared between students' achievements according to each OSCE station they enrolled in. As students' feedback is an important indicator of the success of the learning process, students' feedback about OSCE was also measured. Results: A moderate correlation was observed between students' overall marks in OSCE and that in written exam $\left(r^{2}=0.36 p=0.001\right)$. Prescription station showed a moderate correlation with the written exam $\left(r^{2}=0.30, p<0.001\right)$ and the counseling station showed a weak correlation $\left(r^{2}=0.125, p<0.001\right)$. Whereas no significant correlation $(p=0.3)$ was observed on comparison of the written exam with the online station nor with the communication station. Highest students scores were observed in prescription-based station $16.7 / 20( \pm 3.2)$ whereas the lowest scores were detected in online resourcesbased station $13.4 / 20( \pm 5.8)$. The majority of students were satisfied about the validity and reliability of OSCE. Discussion: A carefully designed development process based on a well-structured blueprint is needed to implement a sophisticated OSCE. The validation and evaluation of an OSCE should performed both quantitatively and qualitatively. A simple diversified OSCE, can serve as a reliable, valid and economically feasible assessment tool of student performance. Together, the traditional written exam and OSCE provide a broad assessment of pharmacy student's skills and knowledge.
\end{abstract}

Key words: OSCE, Doctor of Pharmacy, ambulatory care clerkship, clinical skills, written exam.

\section{INTRODUCTION}

The assessment of clinical competence is fundamental to ensure that graduate pharmacists can exercise their duties in patient care. ${ }^{1}$ Colleges and schools of pharmacy traditionally have assessed students' performance using multiple-choice and essay questions. However, these methods of assessment may not adequately evaluate the mastery of essential skills and measure cognitive learning in clinical settings. ${ }^{2}$ Moreover, often, there is a clear disparity seen between performance of excellent student in the classroom and in clinical settings. ${ }^{2}$ To astound these inadequacies, introduction of performance-based assessment methods, such as the objective structured clinical examination (OSCE) in undergraduate pharmacy education is of fundamental importance. ${ }^{3-5}$

The OSCE was first described by Dr.Harden in the 1970s as a new planned or structured approach for clinical competence assessment. ${ }^{6}$ In this method, a number of stations each of which contains specific clinical scenario are used. Through these stations, students must complete specific clinical tasks. ${ }^{7}$ The
Submission Date: 25-12-2016; Revision Date: 14-03-2017; Accepted Date: 18-03-2017

DOI: 10.5530/ijper.51.3.64 Correspondence: Ali Almuqdadi,

Department of Biopharmaceutics and Clinical Pharmacy,

Faculty of Pharmacy, The University of JORDAN, Amman, 11942, Queen Rania Street, JORDAN. Tel: (+1) 603-275-7179 E mail: ali_1899@yahoo.com

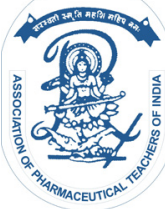

www.ijper.org 
OSCE is long being used for testing clinical skills of medical students and can show medical and nursing students' clinical skills pretty well. ${ }^{8,9}$ In pharmacy schools, this method is being widely used to evaluate the skills of pharmacy students. ${ }^{410}$ For example, an extensive study in USA indicated that $37 \%$ of pharmacy schools use OSCE. In schools not performing this method, faculty members' lack of time was the most common reason. ${ }^{10}$ OSCE has become the gold standard over the world as a tool for evaluating the clinical competency of medical students. ${ }^{8-11}$

Although a well-constructed and implemented OSCE is a valid and reliable method of evaluating clinical competence, ${ }^{12,13}$ there is overwhelming evidence from the literature to support that it is not without limitations. ${ }^{14-16}$ Beside human resources, time consuming issues and managing the complexity of such exam, the method of assessment as well as the examination procedure, may also differ from one OSCE to another. Such wide variations may influence the validity and reliability of the overall examination. ${ }^{10,14,17}$

\section{Objectives}

Our hybrid OSCE had some peculiar elements that needed to be studied. Thus, in our mission to develop a more robust, feasible, reliable, and valid examination in the future, we conducted this study with the purpose of evaluating student performance by the OSCE, Comparing OSCE performance to the traditional written examination for the evaluation of student learning and exploring the satisfaction of students about the use of OSCE.

\section{METHOD}

\section{Study subjects}

Fifty eight students of the sixth-year doctor of pharmacy students who registered in ambulatory care clerkship were involved in OSCE as candidates. They were divided into 4 groups Table 1. Clinical preceptors from our faculty participated as examiners and/or actors. As well as, post graduate students and other master degree holders, in clinical pharmacy program, participated as actors (standardized patients or physicians).

Informed consent: Informed consent was obtained from all individual participants included in the study.

\section{Bioethical commission}

According to the university of Jordan regulations, for this type of study a Bioethical commission approval is not necessary. The work was carried out in accordance with the Declaration of Helsinki and other relevant regulations. There were no risks to human subjects.

\section{OSCE development process}

The Faculty of Pharmacy at the University of Jordan successfully developed, validated, and applied an OSCE in the ambulatory care clerkship of sixth year doctor of pharmacy curricula during the second semester of 2014-2015 academic year. The OSCE has been implemented as an assessment tool for the ambulatory care clerkship students along with the theoretical exam. The OSCE stations were developed further from the first group to the fourth group regarding their number, type (interactive or non-interactive) and contribution to the final mark Table 1. Among the first and second group of students, OSCE was done as a pilot experiment in order to evaluate feasibility of this type of examination. Our OSCE stations were developed by 5 pharmacists who are involved in the teaching process of this clerkship and who had an experience in hospital and community pharmacy practice. OSCE stations were evolved after a well-structured blueprint was developed to ensure that these stations will meet the aims of the exam and required competencies, and that these stations are relevant to practice. Stations were then revised carefully for their contents and scenarios, and their applicability.

To ensure objectivity and consistency among different simulated patients, physicians and the examiners, all actors were trained well for the script in the same standardized training workshop before the exam. They were also provided with written directions so that only specified data is given to each student and specific questions to be asked. To improve inter-rater variability; a new approach was introduced where the simulated patients and physicians have been provided with a reminding checklist for their role in the case scenario. This approach showed a better performance for the actors and the case scenario.

Students have been trained about each station throughout the course, where role plays patient counseling, communications with physicians in clinics, online resources based homework and daily prescription analysis in addition to drugs dispensing were all consistently conducted through the course.

\section{OSCE Setting}

A brief description about the nature and the content of each station, the management of the exam and the mark distribution was provided for the students one week before the exam.

During the exam, 10 minutes were given for each student to perform the required tasks in each station. In the third and fourth groups, there were three copies of each station category with three different simulated patients and physicians in order to save time. A notebook paper 
was provided in each station to permit the student to writes his/her notes. Stations have not been video recorded due to logistic constraints and female-student objection.

At the beginning of each station, and to avoid confusion by students, a brief introduction about the cases for each student was provided within 1 minute to help them to perform the scenario in the predetermined manner. After that an alarm clock rang to announce the start of the task, and then a second alarm rang alerting the time is over and need to move toward the next station, and so on. If the student finished the station before the time for the task; he/she should wait till the alarm rings. All students underwent the exam on the same day under same conditions.

One of the course preceptors was assigned as a general observer to oversee the general flow of the exam.

\section{OSCE scoring}

Checklists of expectations required from students where developed for each interactive station. These checklists were included both analytical and global evaluations and they were used in the scoring process.

\section{Validation and evaluation of the OSCE}

This study utilized different methods to evaluate the OSCE experiment quantitatively and qualitatively to examine the experience along with outcomes.

Students' scores in OSCE were compared with their scores in the theoretical exam. We compared between the theoretical and OSCE results in the third and fourth groups combined with deleting the online part of OSCE in the fourth group in order to maintain consistency between the two groups; also, the online station contributed only marginally to the OSCE mark. We analyzed the correlation between students' achievements in the written exam and their achievements in each OSCE station. We also compared between student achievements among different OSCE stations.

\section{Students' feedback}

After each OSCE, students were asked to fill an 11-questions questionnaire which designed to evaluate OSCE's content, quality, management and environment. The questionnaire used a 5-level likert item to meet students' response to each question ranging from "strongly agree" to "strongly disagree". Face validation of the questionnaire was done by experienced faculty members and educators and a consensus was established.

Students were asked to complete the questionnaire on a voluntary basis immediately after finishing the OSCE, before leaving the examination venue.

\section{Statistical analysis}

Statistical package for the Social Sciences software release 20 (SPSS Inc., Chicago, IL) was used for the statistical analysis to represent the descriptive statistics data and analyze the correlation (Pearson test for parametric and Spearman test for non-parametric data) and difference (paired t test) between the written exam and OSCE. The level of significance was set at $p<0.05$. Data was represented as mean $( \pm \mathrm{SD})$.

\section{RESULTS \\ Description}

Total of fifty-eight pharm D students, divided into four student's groups throughout the course, enrolled in this study and undergone OSCE and written exams as final exam of ambulatory care clerkship. Fifteen of them (pilot group) underwent a one station- pilot OSCE, a patient counseling station. Twenty-three of them (group 3) undergone three stations-OSCE; and a fourth station (use of online resources) was added in the fourth group (20 students) (Table 1).

Students' achievements in written exam and OSCE, and in each station are summarized in Table 2. Highest scores were in prescription-based station 16.7 ( \pm 3.2) whereas the lowest were in online resources- based station 13.4 ( \pm 5.8).

\section{Comparisons of OSCE with the written exam}

There was no statistical significant difference between students' marks in OSCE (group 3+4) and that in written exam $(p=0.12)$, non-significant difference $(p>0.05)$ was also observed between OSCE and written exam among each individualized OSCE student groups (pilot, third or fourth group) Table 3. A moderate correlation was observed between students' marks in OSCE (group $3+4)$ and that in written exam $\left(\mathrm{r}^{2}=0.36, p=0.001\right)$. Among each of the three groups (pilot, third and fourth group), only the fourth group showed a significant correlation with the written exam $(\mathrm{p}<0.05)$ and the correlation was higher in absence of online station $\left(\mathrm{r}^{2}=0.36, \mathrm{p}=0.01\right)$ than in the presence of this station $\left(\mathrm{r}^{2}=0.23, \mathrm{p}=0.03\right)$ Table 3 .

The degrees of correlation between students' achievements in the written exam and their achievements in each OSCE station ranged from weak to moderate. Prescription station showed a moderate correlation with the written exam $\left(r^{2}=0.30, p<0.001\right)$ and the counseling station showed a weak correlation $\left(\mathrm{r}^{2}=0.125\right.$, $p<0.001)$. Whereas non-significant correlation $(p=0.3)$ where observed in both online and communication stations. Only the online station showed a significant 


\begin{tabular}{|c|c|c|c|c|c|}
\hline Group no. & $\begin{array}{l}\text { Number of } \\
\text { candidates }\end{array}$ & $\begin{array}{l}\text { Number of } \\
\text { OSCE stations }\end{array}$ & $\begin{array}{l}\text { Types of OSCE } \\
\text { stations }\end{array}$ & $\begin{array}{l}\text { Description of stations and their } \\
\text { contents }\end{array}$ & $\begin{array}{l}\text { Contribution to } \\
\text { the final exam } \\
\text { mark }\end{array}$ \\
\hline Group 1 & 7 & 1 & Interactive & $\begin{array}{l}\text { A patient who comes to a community } \\
\text { pharmacy and asks for an OTC } \\
\text { medication for his condition }\end{array}$ & $20 \%$ \\
\hline Group 2 & 8 & 1 & Interactive & $\begin{array}{l}\text { A patient with a prescription that needs } \\
\text { to be filled and counseled about }\end{array}$ & $20 \%$ \\
\hline \multirow[t]{3}{*}{ Group 3} & \multirow[t]{3}{*}{23} & \multirow[t]{3}{*}{3} & \multirow[t]{2}{*}{ Interactive } & $\begin{array}{l}\text { A patient who comes to a community } \\
\text { pharmacy and asks for an OTC } \\
\text { medication for his condition }\end{array}$ & \multirow[t]{3}{*}{$37.5 \%$} \\
\hline & & & & $\begin{array}{l}\text { A physician who asks the pharmacist } \\
\text { for a consult regarding his patient's } \\
\text { condition }\end{array}$ & \\
\hline & & & Non interactive & $\begin{array}{l}\text { A written prescription that need to be } \\
\text { analyzed }\end{array}$ & \\
\hline \multirow[t]{4}{*}{ Group 4} & \multirow[t]{4}{*}{20} & \multirow[t]{4}{*}{4} & \multirow[t]{2}{*}{ Interactive } & $\begin{array}{l}\text { A patient who comes to a community } \\
\text { pharmacy and asks for an OTC } \\
\text { medication for his condition }\end{array}$ & \multirow[t]{4}{*}{$42.5 \%$} \\
\hline & & & & $\begin{array}{c}\text { A physician who asks the pharmacist } \\
\text { for a consult regarding his patient's } \\
\text { condition }\end{array}$ & \\
\hline & & & \multirow[t]{2}{*}{ Non-interactive } & $\begin{array}{l}\text { A written prescription that need to be } \\
\text { analyzed }\end{array}$ & \\
\hline & & & & $\begin{array}{l}\text { A controversial question that need to be } \\
\text { answered using online resources }\end{array}$ & \\
\hline
\end{tabular}

Table 2: Descriptive statistics of Objective Structured Clinical Examination (OSCE) stations and written exam for the third and fourth group

\begin{tabular}{|c|c|c|c|c|}
\hline Test/ station & N & Minimum* $^{*}$ & Maximum* $^{*}$ & Mean (Std. Deviation) \\
\hline Written exam & 43 & 9.00 & 20 & $16.4(2.2)$ \\
\hline OSCE & 43 & 10.00 & 20 & $15.7(2.2)$ \\
\hline Counselling station & 43 & 8.00 & 20 & $15.5(2.5)$ \\
\hline Communication station & 43 & 8.00 & 20 & $15.8(2.8)$ \\
\hline Prescription station & 43 & 7.00 & 20 & $16.7(3.2)$ \\
\hline Online station - & 20 & 0.00 & 20 & $13.4(5.8)$ \\
\hline
\end{tabular}

*out of 20 ,

- Only in forth group.

\begin{tabular}{|c|c|c|c|c|}
\hline \multicolumn{2}{|c|}{ Table 3: Association between students' achievements of OSCE and of written exam } \\
\hline Student group & $\mathbf{N}$ & Correlation $\mathbf{r}^{*}$ & $\boldsymbol{p}$ value of correlation & $\begin{array}{c}\boldsymbol{p} \text { value of paired } \\
\text { t- test }\end{array}$ \\
\hline OSCE of groups 1+2 (pilot group) & 15 & 0.37 & 0.17 & 0.12 \\
\hline OSCE of group 3 & 23 & 0.36 & 0.08 & 0.45 \\
\hline OSCE of group 4 (without online station) & 20 & 0.6 & 0.01 & 0.18 \\
\hline OSCE of group 4 (with online station) & 20 & 0.48 & 0.03 & 0.06 \\
\hline OSCE of group 3+4 & 43 & 0.6 & 0.002 & 0.12 \\
\hline Counseling station group 3+4 & 43 & 0.5 & $<0.001$ & 0.07 \\
\hline Communication station group 3+4 & 43 & 0.17 & 0.3 & 0.27 \\
\hline Prescription station group 3+4 & 43 & 0.55 & $<0.001$ & 0.5 \\
\hline Online station group 3+4 & 20 & 0.24 & 0.3 & 0.02 \\
\hline
\end{tabular}

*Pearson test for parametric and Spearman test for non-parametric data. 


\begin{tabular}{|c|c|c|c|c|c|}
\hline \multicolumn{7}{|c|}{ Table 4: Students' feedback about the OSCE } \\
\hline Questionnaire Item & \multicolumn{5}{|c|}{ Response } \\
\hline Points of evaluation & $\begin{array}{c}\text { Strongly } \\
\text { agree N (\%) }\end{array}$ & $\begin{array}{c}\text { Agree } \\
\text { N (\%) }\end{array}$ & $\begin{array}{c}\text { Uncertain } \\
\text { N (\%) }\end{array}$ & $\begin{array}{c}\text { Disagree } \\
\text { N (\%) }\end{array}$ & $\begin{array}{c}\text { Strongly disagree } \\
\text { N (\%) }\end{array}$ \\
\hline Appropriateness of contents & $10(29.4)$ & $21(61.8)$ & $1(2.9)$ & $1(2.9)$ & $1(2.9)$ \\
\hline Quality of the exam & $8(23.5)$ & $21(61.7)$ & $4(11.7)$ & $1(2.95)$ & $0(0)$ \\
\hline Case scenarios & $11(32.4)$ & $18(52.9)$ & $2(5.8)$ & $2(5.9)$ & $1(2.9)$ \\
\hline Time allowed & $11(32.3)$ & $11(32.3)$ & $3(8.8)$ & $5(14.7)$ & $4(11.8)$ \\
\hline Difficulty appropriateness & $4(11.8)$ & $26(76.5)$ & $1(2.95)$ & $2(5.9)$ & $1(2.9)$ \\
\hline Wims of the course were met by the exam & $14(41.2)$ & $18(52.9)$ & $2(5.9)$ & $0(0)$ & $0(0)$ \\
\hline Exam the exam helpful? & $13(38.2)$ & $19(55.9)$ & $1(2.95)$ & $1(2.95)$ & $0(0)$ \\
\hline Expropriateness of the exam environment & $10(29.4)$ & $21(61.7)$ & $1(2.9)$ & $1(2.9)$ & $1(2.9)$ \\
\hline Was the OsCE a good experience? & $10(29.4)$ & $17(50)$ & $6(17.6)$ & $0(0)$ & $1(2.9)$ \\
\hline
\end{tabular}

difference $(p=0.02)$ with the written exam achievement (Table 3).

\section{Students' feedback}

Most students of group 3+4 agreed (or strongly agreed) with most of questions that aimed to assess validity and reliability of OSCE. The only exception was time management of OSCE station, where a considerable number of students $(26.5 \%)$ believed that there was inappropriateness in time allowed for each station. Whereas most of students were satisfied with OSCE content quality and reliability (Table 4).

\section{DISCUSSION}

Although preparing students to become qualified pharmacists who can provide pharmaceutical care in a variety of health care settings is the primary mission of pharmacy education, the evaluation of the clinical skills needed to provide this type of care remains elusive. ${ }^{2}$

OSCE is commonly used to evaluate the knowledge and skills needed for pharmacy clerkship. ${ }^{10-18}$

Unfortunately, this method is not widely used in Jordan pharmacy faculties to evaluate pharmacy students.

Hence, this study was a vital tool to describe, validate and assess the implementation and development process of an OSCE in a pharmacy curriculum in Jordan.

\section{OSCE and theoretical comparison}

A few studies have compared the performance of pharm D students in written exams to that in OSCE. ${ }^{2-19}$ We observed a weak- moderate correlation between score achievement in OSCE and in written exam, this finding is consistent with many reports that show a weak-moderate correlation between the written exam and OSCE. ${ }^{2-19}$

Gardner and colleagues reported a moderately correlation ( $\mathrm{r}=0.58, p>0.05)$ between performances on the 2 examinations. ${ }^{2}$ Similarly, Kriton and colleagues found a moderate correlation ( $\mathrm{r} 0.6, \mathrm{p}<0.05)$ for assessment of a third-year culminating OSCE and multiple-choice examination. ${ }^{19}$

Although some other studies showed no correlation between the written exam and OSCE, ${ }^{18-20}$ the degree of correlation may depend on many factors such as the content and the aims of OSCE and written exam used, type of the exam material, the method of assessment used in OSCE or level of the students who are examined. Despite some controversy about the degree of correlation between the OSCE and written exam in different studies, Comparisons between these studies are not definitive and most reports show a disparity between traditional and clinical setting exams. ${ }^{2}$ This can be attributed to the fact that OSCE evaluate different measures such as critical thinking and clinical skills that written exams can't fully assess. These skills can better identify student's achievement in clinical setting that need to be incorporated in pharmacy exams to evaluate student performance in real practice. ${ }^{2-18}$ Royal Pharmaceutical Society of Great Britain (RPSGB) in conjunction with University of East Anglia, have showed a poor correlation between academic achievement and performance during the preregistration year. ${ }^{21}$

It has been speculated that a larger number of stations within OSCE module may strengthen the relationship between the written exam and OSCE performance, ${ }^{2}$ but it appears that it is the type and not the number of stations that affect the correlation between OSCE 
and written exam. For example, when we analyzed the fourth group with and without online station, which assess students based on a pure skill not knowledge, correlation with written exam was lower in the presence of online station $\left(r^{2} 0.23\right)$ than the correlation without this station $\left(r^{2} 0.36\right)$, this station also was the only station that showed a significant difference with the written exam. In addition, there was no significant correlation $(p=0.3)$ between both communication and online stations (that were assessed mainly based on skills) with the written exam; while prescription station (as a written and knowledge based station) showed a good correlation with the written (Table 3).

\section{Individual OSCE stations achievement}

The highest achievement in group $3+4$ belonged to prescription station, this may be attributed to the fewer skills needed for this station and may explain the highest correlation between this station and the written exam. The lowest achievement was in online station (only group 4), this may explain the non-significant correlation and the significant difference $(p=0.02)$ of this station with written exam as it assesses mainly clinical skills and not knowledge. These results may indicate a need to emphasize, in practice and learning process, on these important clinical skills.

In spite of some variations in average scores between individual stations that were found for some areas, the overall results were more similar than expected, this finding is consistent with another study that compared between different OSCE stations. ${ }^{20}$

OSCE achievements among third and fourth groups were similar, indicating the consistency of OSCE design even with different number of stations used.

\section{The interpatient and interrater variability}

The interpatient and interrater variability could be true sources of bias as documented by previous studies. ${ }^{22,23}$

Although a larger number of stations has been used to increase the reliability of OSCE in a high-stake setting (such as The Pharmacy Examining Board of Canada's Qualifying Examination), ${ }^{14}$ a small OSCE station number, in conjunction with the written exam, can serve as a reliable, valid and economically feasible global assessment method of student performance. . $^{18,20}$

Although we did not conduct any interrater reliability testing, the similarity in the exam scores indicated that the interrater and interpatient variability didn't affect reliability of the exam.

However, it should be noted that OSCE is contextual and the assessment method should ideally reflect how students will perform in real clinical settings when they are not being observed. ${ }^{24}$

\section{OSCE student satisfaction}

Student satisfaction regarding OSCE was high in almost all parts of the survey, students were highly satisfied about the content of the exam, and scenarios of cases and their quality as well as the management process of the exam, students were also highly satisfied about the correlation between the aims of the course with the exam. Although the satisfaction about the appropriateness of the exam environment was somewhat low, this can be improved in future by dividing the student's exam into two sessions to decrease the number of students per each exam session, these finding show that OSCE can be applied in simplified and low cost mode and in a valid manner.

The students were satisfied about the difficulty of the exam, students' views on fairness and difficulty of the exam may not necessarily be consistent with other published literature ${ }^{20}$ and these findings must not be interpreted in isolation.

Students was somewhat less satisfied about the time allowed to perform the exam, this problem will be taken into account in the future to increase time per each station to 15 minutes that used in some pharmacy OSCE programs, but it may be related to students' naivety to this method of assessment where it has been shown that many students felt that the OSCE was a highly anxiety-producing exam, more stressful than other types of examinations and should be introduced earlier in the curriculum. ${ }^{20}$

Students highly agreed that OSCE was a helpful exam to them, they also indicated that they had a good experience with such exam and felt that OSCE evaluated their counseling skills in a good way. These findings were consistent with similar studies reported that overwhelming proportion of the students saw the OSCE as a good opportunity to simulate real-life scenarios and provided a useful practical learning experience and feedback to evaluate their strengths and weaknesses in clinical skills. ${ }^{3-20}$

\section{CONCLUSION}

Together, the traditional written exam and OSCE provide a broad assessment of pharmacy practice competencies. A low OSCE station number, can serve as a reliable, valid and economically feasible assessment tool of student performance.

Although it is our first time experienced, our work showed a positive impact among students and faculty 
members and opens the door for the use of OSCE in pharmacy faculties in Jordan.

\section{Future task}

For generalization of study outcomes, the conduction of this type of exam with more number of stations and among larger number of students, in other universities and, if possible, in other clerkships is required. So, future implementation of the exam on larger number of students and in other pharmacy faculties in strongly encouraged in the future.

\section{Limitation of the study}

This study was conducted in only one university in Jordan where different variable could be present that could affect the outcomes. In addition, a higher number of students are required for generalization of the results. Finally, our study measure only short term feedback about the exam, whereas, a long-term feedback measure such as the feedback of the graduate students in job market and employer feedback about the advantages of the exam is important for the validation of the exam in the future and this point should be considered in future work.

Financial disclosure: No financial sponsor to report

\section{ACKNOWLEDGEMENT}

We acknowledge with thanks all patients/actors, staff members, and lecturers involved in the OSCE. Authors also grateful to Joman Mahmod for her edition and proofing assistance.

\section{CONFLICT OF INTEREST}

The authors declare that they have no conflict of interest.

\section{ABBREVIATION USED}

OSCE: objective structured clinical examination; RPSGB: Royal Pharmaceutical Society of Great Britain

\section{REFERENCES}

1. Rutter PM. The introduction of observed structured clinical examinations (OSCEs) to the M.Pharm. degree pathway. Pharmacy Education. 2002;1(3):173-80. https://doi.org/10.1080/15602210210345.

2. Gardner SF, Stowe CD, Hopkins DD. Comparison of traditional testing methods and standardized patient examinations for therapeutics. The American Journal of Pharmaceutical Education. 2001; 65(3):236-324.

3. Awaisu A, Nik Mohamed MH, Al-Efan QAM. Perception of pharmacy students in Malaysia on the use of objective structured clinical examinations to evaluate competence. The American Journal of Pharmaceutical Education. 2007;71(6):118. https://doi.org/10.5688/aj7106118; PMid:19503702.

4. Corbo M, Patel JP, Abdel Tawab R, Davies JG. Evaluating clinical skills of undergraduate pharmacy students using objective structured clinical examinations (OSCEs). Pharmacy Education. 2006; 6(1):53-8. https://doi. org/10.1080/15602210500528372.

5. Rees JA, Collett JH, Crowther I, Mylrea S. Assessment of competence using a structured objective examination approach. The Pharmaceutical Journal. 1991;247(Supp. Oct. 12):R32.

6. Harden RM. What is an OSCE?. Medical Teacher. 1988;10(1):19-22. https:// doi.org/10.3109/01421598809019321; PMid:3221760.

7. McAleer S, Walker R. Objective structured clinical examination (OSCE). Occasional paper (Royal College of General Practitioners). 1990;(46):39-42. PMid:1670207 PMCid:PMC2560106.

8. Patricio MF, Juliao M, Fareleira F, Carneiro AV. Is the OSCE a feasible tool to assess competencies in undergraduate medical education? Medical Teacher. 2013;35(6):503-14. https://doi.org/10.3109/0142159X.2013.774330: PMid:23521582.

9. Rushforth HE. Objective structured clinical examination (OSCE): review of literature and implications for nursing education. Nurse Education Today. 2007;27(5):481-90. https://doi.org/10.1016/j.nedt.2006.08.009; PMid:17070622.

10. Sturpe DA. Objective structured clinical examinations in doctor of pharmacy programs in the United States. American Journal of Pharmaceutical Education. 2010;74(8):148 https://doi.org/10.5688/aj7408148; PMid:21179259 PMCid:PMC2987288.

11. Pierre RB, Wierenga A, Barton M, Branday JM, Christie CD. Student evaluation of an OSCE in paediatrics at the University of the West Indies, Jamaica. BMC Medical Education. 2004;4(1):22. DOI 10.1186/1472-6920-4-22. https://doi.org/10.1186/1472-6920-4-22.

12. Carraccio $\mathrm{C}$, Englander $\mathrm{R}$. The objective structured clinical examination, a step in the direction of competency-based evaluation. Archives of Pediatrics and Adolescent Medicine Journal. 2000;154(7):736-41. https://doi. org/10.1001/archpedi.154.7.736.

13. Woodburn J, Sutcliffe N. The reliability, validity and evaluation of the objective structured clinical examination in podiatry. Assessment \& Evaluation in Higher Education.1996; 21:131-47. https://doi.org/10.1080/0260293960210203.

14. Austin Z, O'Byrne C, Pugsley J, Munoz L. Development and validation processes for an objective structured clinical examination (OSCE) for entryto-practice certification in pharmacy: the Canadian experience. The American Journal of Pharmaceutical Education. 2003;67(3): Article 76, 1-8.

15. Troncon LE. Clinical skills assessment: limitations to the introduction of an "OSCE" (objective structured clinical examination) in a traditional Brazilian medical school. Sao Paulo Medical Journal. 2004;122(1):12-17. https://doi. org/10.1590/S1516-31802004000100004; PMid:15160521.

16. Walters $K$, Osborn D, Raven P. The development, validity and reliability of a multimodality objective structured clinical examination in psychiatry. Medical Education. 2005 Mar; 39(3):292-8. https://doi.org/10.1111/j.13652929.2005.02091.x; PMid:15733165

17. Stowe CD, Gardner SF. Real-time standardized participant grading of an objective structured clinical examination. The American Journal of Pharmaceutical Education. 2005; 69(3):272-6. https://doi.org/10.5688/ aj690341.

18. Kouti L, khezrian M., Eslami A, Assarian M, Zargar H, Mahdavinia M, Kazemi M, Eslami K. Designing Objective Structured Clinical Examination in Basic Community Pharmacy Clerkship Course and Assessment of Its Relationship with Conventional Exam. Journal of Pharmaceutical Care. 2014;2(3):110-3.

19. Kirton SB, Kravitz L. Objective structured clinical examinations (OSCEs) compared with traditional assessment methods. The American Journal of Pharmaceutical Education. 2011;75(6):111. https://doi.org/10.5688/ ajpe756111; PMid:21931449 PMCid:PMC3175669.

20. Salinitri FD, O'Connell MB, Garwood CL, Lehr VT, Abdallah K. An Objective Structured Clinical Examination to Assess Problem-Based Learning, The American Journal of Pharmaceutical Education. 2012;76(3):44. https://doi. org/10.5688/ajpe76344; PMid:22544961 PMCid:PMC3327242.

21. Wright D, Loftus M, Christou M, Eggleton A, Norris N. RPSGB - Healthcare professional education and training: how does pharmacy in Great Britain compare? Royal Pharmaceutical Society of Great Britain, London, 2006.

22. McLaughlin K, Gregor L, Jones A, Coderre S. Can standardized patients replace physicians as OSCE examiners? BMC Medical Education. 2006; 6 : 12. DOI 10.1186/1472-6920-6-12. https://doi.org/10.1186/1472-6920-6-12. 
PICTORIAL ABSTRACT

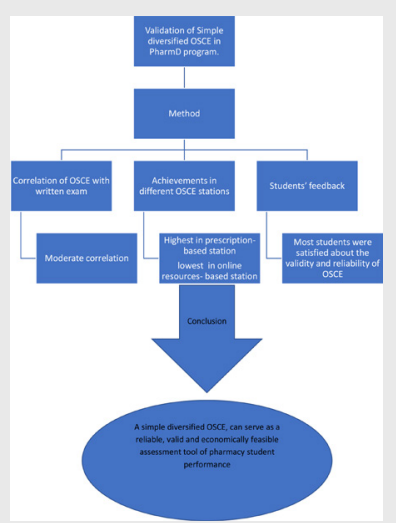

\section{SUMMARY}

OSCE provide a valid assessment tool to evaluate clinical skills for pharmacy students. A carefully designed development process based on a well-structured blueprint is needed to implement a sophisticated OSCE. The validation and evaluation of an OSCE should performed both quantitatively and qualitatively. The OSCE should be designed according to the specific predetermined aims in order to minimize inconsistency. Our study shows that a small OSCE station number, can serve as a reliable, valid and economically feasible assessment tool of student performance. Finally, our work opens the door for the use of OSCE in pharmacy faculties in Jordan.

\section{About Authors}

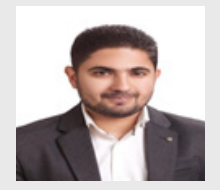

Ali Almuqdadi: Is a preceptor at the university of Jordan, Faculty of Pharmacy, he had a Bachelor of Sciences degree in Pharmacy from Isra university in 2011 and he received the Master degree in clinical pharmacy from the University of Jordan in 2014. He has experience in pharmacy education.
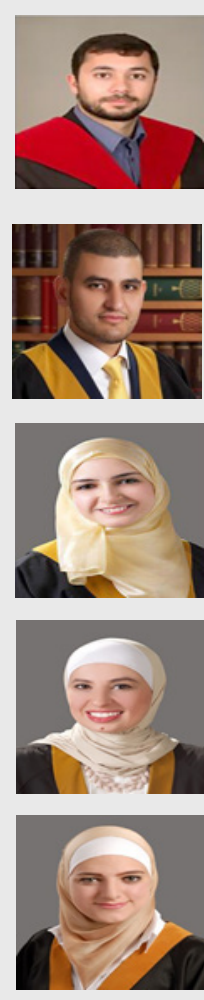

Al-Motassem Yousef: Is Professor of Pharmacology and Therapeutics, he is the EX- Dean's Assistant for PharmD Program \& Hospital Affairs, currently he is Associate Dean for Quality Control and Development, Department of Biopharmaceutics and Clinical Pharmacy, College of Pharmacy/ Jordan University. He obtained his Ph. D. degree in 2002 from University of South Carolina/College of Pharmacy (USA). He has experience in the areas of Pharmacy Care and Molecular pharmacology and he has several publications in these areas.

Khalil Majdalawi: Is a preceptor at the university of Jordan, Faculty of Pharmacy. He has a Master degree in clinical pharmacy from the University of Jordan.

Zeina Masoud: Is a preceptor at the university of Jordan, Faculty of Pharmacy. She has PharmD degree from the University of Jordan.

Reem Kalabani: Is a preceptor at the university of Jordan, Faculty of Pharmacy. She has a Master degree in clinical pharmacy from the University of Jordan.

Hanadi Al-hadeed: Is a preceptor at the university of Jordan, Faculty of Pharmacy. She has PharmD degree from the University of Jordan.

Cite this article: Almuqdadi A, Yousef AM, Majdalawi K, Masoud Z, Kalabani R, hadeed HA. Validation and Evaluation of an OSCE in Undergraduate Doctor of Pharmacy Program. Indian $\mathrm{J}$ of Pharmaceutical Education and Research. 2017;51(3):380-7. 